\title{
Research and Analyze the Factors Affecting to the Formation of the Economy Area of Fresh Vegetables Cultivation at Ho Chi Minh City Suburb
}

\author{
Pham Duc Trung \\ Department of Natural Resources \& Environment Economic, Ho Chi Minh City University of Natural Resources \& Environment, Ho \\ Chi Minh City 760000, Vietnam
}

\begin{abstract}
Vietnam's economy is developing more and more rapidly, people's income are increasing, and the living condition is better. Today, consumer are increasingly aware of the quality of products, especially fresh food, but they have a little opportunity to choose the products which satisfy the needs, because they are limited to the product information and product origin. Fresh vegetables are one of the essential foods in the family living. The selection of fresh vegetables is not only to serve the basic needs as eating and drinking, but also to include the need for safety. Currently, consumer demand for fresh vegetable are great, especially when the living standards are becoming higher and people pay more attention to their health, especially for the consumer of Ho Chi Minh City. How fresh is vegetable market in Ho Chi Minh City today like? What is consumers' awareness of fresh vegetable? What factors impact the fresh vegetable buying behavior of consumers? Why does the development of fresh vegetable market in Ho Chi Minh City currently face many difficulties? This study surveys the research, analyzes the factors affecting the economic area formation of fresh vegetable plantation at suburb of Ho Chi Minh City.
\end{abstract}

Key words: Formation factors, the economic area of green vegetables cultivation, Ho Chi Minh City suburbs.

\section{Introduction}

Ho Chi Minh city is the largest city in Vietnam with a population of nearly 10 million people, and there are many international organizations. Demand for food such as vegetables, meat, fish and other items are great. According to the Department of Agriculture and Rural Development of Ho Chi Minh city [1], the current fresh vegetable market is quite large especially in current period when economic conditions are developing and integrating; shaping economic sector of fresh vegetable plantation to meet the requirement of the need with the high quality, especially in Ho Chi Minh city. Furthermore, it meets the export need of Ho Chi Minh city in Vietnam.

Ho Chi Minh city is a city of industry and services; it cannot meet the needs of people on food for several

Corresponding author: Pham Duc Trung, Ph.D., main research field: economic, marketing, finance and bank. reasons. The first reason is the rapid pace of urbanization, and the regional economic land of fresh vegetable plantation decreased over the time. The second reason is that: part of labor in the economic area of fresh vegetable plantation has lower income than other service branches [1,2].

With these characteristics, Ho Chi Minh city had to face many difficulties and challenges which has the forming problem of the economic land region of fresh vegetable plantation and domestic consumption markets of fresh vegetable and export to meet the need of society $[1,2]$.

\section{Subjects, Method and Data of Study}

- To identified customers that they have the need to use daily fresh vegetables to meet the requires;

- To study and determine mainly basic factors; and to propose the development of the economic area formation of fresh vegetable plantation at suburb of $\mathrm{Ho}$ 
Chi Minh city and economic efficiency of fresh vegetable farmers, agricultural service cooperatives, and state authorities;

- To survey and direct interview of customers in some areas of Ho Chi Minh city [3].

- It applies comparison method of datasheet, analysis of comparable statistic index to achieve the study objectives.

\subsection{Sample and Design of Study}

- To select and survey a sample size of 220 customers who are determined to have the need to use green vegetables in daily;

- Age: To select consumers up 25 to 60 ages with 155 males and 65 females by gender.

\subsection{Scope of Study}

This project studies some suburban county such as District 12, Hoc Mon and Thu Duc, Binh Chanh, $\mathrm{Cu}$ Chi where it has the economic land area of fresh vegetable cultivation [3,4] and District 1, 3 and Tan Binh with the location of concentrated residents, in which the living standards of people is high.

\subsection{Economic Area Situation of Fresh Vegetable Plantation}

According to a report carried out in a fresh vegetable program in Ho Chi Minh city area of Department of Agriculture and Rural Development, the current economic area of cultivated surface of over 8,000 hectares with vegetables output of about 180,000 tonnes/year concentration in the suburban such as $\mathrm{Cu}$ Chi, Hoc Mon, Binh Chanh district 12 [1, 2]. Fresh vegetable demand of this city is great about
1,800-2,000 tons/days vegetables and all kinds of fruits. The ability to produce vegetables of city is only about $30-40 \%$ of the demand, and the rest must be imported from neighboring provinces such as Da Lat, and Long An.

2.4 Development Plan of Economic Land for Area under Fresh Vegetables Cultivation in Ho Chi Minh City per Years [1, 2]

\subsection{Planning of Economic Land Area of Fresh Vegetables Plantation}

The planning of land use of agricultural economics of Ho Chi Minh city is in accordance with the annual plan increased compared to the previous year in Table $1[1,2]$. Furthermore, urban land area by 2020 will be divided into economic regions of fresh vegetable production and the area of rotational crop land with other trees and then there is an agreement of district about conversion of each region.

\subsection{The Situation of Fresh Vegetable Consumption and Economic Efficiency in Traffic and Business of Fresh Vegetables Cultivation}

In recent years, the demand for fresh vegetable use is growing in domestic, as consumers are more aware of fresh vegetable products to ensure their health care. On that basis, cultivation farmer households (with area economy growing vegetables) have appreciated and realized economic efficiency of fresh vegetable cultivation higher than normal vegetables in the same space of time. The average vegetable consumption use is $300 \mathrm{~g}$ per person in a day under guideline of Nutrition Center of Ho Chi Minh city [5].

Table 1 Economic land for area under fresh vegetable cultivation. (Unit : ha)

\begin{tabular}{lllllll}
\hline Area of District & Year of 2005 & Year of 2006 & Year of 2007 & Year of 2008 & Year of 2009 & Year of 2010 \\
\hline Binh chanh & 813 & 900 & 100 & 1,100 & 1,200 & 1,300 \\
Cu chi & 882 & 1,600 & 2,870 & 2,470 & 2,950 & 3,400 \\
Hoc Mon & 300 & 400 & 500 & 650 & 750 & 900 \\
Others & 240 & 240 & 200 & 150 & 100 & 100 \\
Total & & 3,140 & 3,670 & 4,370 & 5,000 & 5,700 \\
Increased & 905 & 530 & 700 & 630 & 700 \\
\hline
\end{tabular}

Source: Department of Agriculture and Rural Development, Ho Chi Minh city. 
Currently, according to Department of Agriculture and Rural Development, Ho Chi Minh city [1], the area of economy land of fresh vegetable cultivation can only provide $30-40 \%$ fresh vegetable of the demand of; the rest $70 \%$ in the market are supplied from other provinces such as Dalat, Long An. Thus, quality management of area economic land for fresh vegetable cultivation in business and circulation also plays a very important role.

\section{Results}

\subsection{Factors Affecting to the Formation of Area of} Economy Land of Fresh Vegetable Cultivation

The survey showed a number of major factors affecting consumers purchasing decision of fresh vegetables including prices information on products and the negative impacts of unsafe vegetables on consumer health, brand of manufacturers and distributors, fresh vegetable selling location, and consumer income [3].

\subsection{General Characteristics of Age, Education Level,} Income of Consumers by Gender

\subsubsection{Age}

The survey of 220 people in districts 1, 3 and Tan Binh in Table 2 [3] showed that the rate of people's income aged of 31-50 is very high; this is the number of people with education level. They are consumers to contribute to society and are prospective. Thus, age is an important factor in the individual consumption policy.

\subsubsection{Education Level}

The result in Table 2 divided education level into groups such as university, high school and high school junior. This is one of the main factors affecting the consumer income of affected. This means decisions of consumers when they select fresh vegetables and other foods; On the other hand, consumers with higher education level are more aware of the quality.

\subsection{According to Decision-2014 of People Committee of HCM City}

In early 2014, Ho Chi Minh city People's Committee issued the Standard of New Poverty (period 2014-2015), which was applied the income of $16,000,000 \mathrm{VND}$ for poor people in a year or less and 16-21 million VND for poor households in a year [6].

Through the survey, income levels at Tan Binh District, 1 and 3 are higher than the poverty line and there are no poor people that author investigated. The level of highest income consumer with 6 million per month accounted for $20.5 \%$ and the lowest income consumer with 3 million per month accounted $35.4 \%$ [3]. The reason they have the different income is due to many factors such as operating in many different industry sectors, education level and professionals. For people with high incomes, they will select and buy delicious products with high quality and fresh vegetables

Table 2 The general of education level and age group of consumer members by sex and by income.

\begin{tabular}{|c|c|c|c|c|c|}
\hline Factors & Aged group & Number of survey consumer $(\mathrm{N}=220)$ & Male & Female & Rate $\%$ \\
\hline \multirow[t]{4}{*}{ Age } & $51-60$ & 10 & 1 & 9 & 4.50 \\
\hline & $41-50$ & 60 & 6 & 54 & 27.2 \\
\hline & $31-40$ & 100 & 10 & 90 & 45.6 \\
\hline & $25-30$ & 50 & 5 & 45 & 22.7 \\
\hline \multirow[t]{2}{*}{ Total } & & 220 & 22 & 198 & $100 \%$ \\
\hline & Education Level & Number of survey consumer $(\mathrm{N}=220)$ & Male & Female & \\
\hline \multirow[t]{3}{*}{ Education level } & University & 70 & 14 & 56 & 31.8 \\
\hline & High school & 113 & 26 & 87 & 51.4 \\
\hline & Junior high school & 37 & 6 & 31 & 16.8 \\
\hline Total & & 220 & 46 & 174 & $100 \%$ \\
\hline
\end{tabular}

Source: the surveyed area of author in 2016. 
Table 3 Monthly average income per surveyed consumer groups. (Unit: 1.000 VND)

\begin{tabular}{lll}
\hline Monthly average income per consumer & Number of surveyed consumer $(\mathrm{N}=220)$ & Rate $\%$ \\
\hline $5.000-6.000$ & 45 & 20.5 \\
$4.000-4.900$ & 97 & 44.1 \\
$3.000-3.900$ & 78 & 35.4 \\
Total & 220 & $100 \%$ \\
\hline
\end{tabular}

Source: the surveyed area of author in 2016.

to protect their own health and family members. Through the survey, authors can realize that, with the level of income in Table 3, consumers are able to spend money on food and drink, fresh vegetables for their families and themselves.

\subsection{General Characteristics of Consumer Behavior}

In consumption goods, they are divided into four mainly basic categories as: daily use, selective, special need and passive demand. Each category of commodity will give consumers a different way of purchasing forms and decision. For daily use items, people do not have to think much to compare them with each others. Usually their values are low compare to the income of consumers and the level of restoration purchase [3].

The type of daily consumption goods are commonly fresh vegetables, meat and fish. Thus, the quality, price and service will be the factors affecting consumers deciding what type of products they should purchase.

The results of the price survey of some commodities in the supermarkets and traditional markets proved that the prices of consumption goods have increased in 2016 compared to that in 2015 . Hence expenditures on foods in Table 4 do not affect monthly income of the client [3].

\subsection{The Issue of Product Information}

Consumers will not buy fresh vegetables if information is not clear with the higher; so they will often choose to buy normal vegetable with low price. Price survey data in Table 5 showed that all consumers have the same opinion unable to distinguish fresh vegetables with normal vegetable [3]. A few consumers can reply how to distinguish fresh vegetables mainly based on the feeling. Thus, authors need to enhance the information knowledge dissemination of fresh vegetable for consumers to understand the differences, from that they can realize more. That is the basis for consumer to choose more fresh vegetables.

Table 4 The commodity summary of the price movement effects on summer groups. $(\mathrm{N}=220$ consumers) (Unit: 1,000 VND/Kg)

\begin{tabular}{|c|c|c|c|c|c|}
\hline Priority food Scale ranking group & $\mathrm{N}=220$ & Types of commodities & Price of year 2015 & Price of year 2016 & Increase \\
\hline 1 & & Meat, fish & 90 & 110 & 20 \\
\hline 2 & & Rice & 12 & 15 & 3 \\
\hline 3 & & Fresh vegetables & 18 & 25 & 7 \\
\hline 4 & & Others & - & - & - \\
\hline Total & $\mathrm{N}=220$ & & & & \\
\hline
\end{tabular}

Source: the surveyed area of author in 2016.

Table 5 The information of fresh vegetable products affected to consumer psychology. $(N=220)$

\begin{tabular}{llll}
\hline Factors & Number of surveyed consumer $(\mathrm{N}=220)$ & Yes & No \\
\hline Less information & 56 & Yes & - \\
High price & 72 & Yes & - \\
Unguarantee quality & 92 & Yes & - \\
Total & 220 & & \\
\hline
\end{tabular}

Source: the surveyed area of author in 2016. 
Table 6 The information of fresh vegetable brand business affected to consumer psychology. $(\mathrm{N}=\mathbf{2 2 0})$

\begin{tabular}{llll}
\hline Fresh vegetable brand business areas & Number of consumer & Guarantee & Unguarantee \\
\hline Supermarket & 120 & Yes & - \\
Traditional markets & 95 & - & Yes \\
Others & 5 & - & Yes \\
Total & 220 & & \\
\hline
\end{tabular}

Source: the surveyed area of author in 2016.

According to the survey result in Table 6 , most consumers buy fresh vegetables in supermarkets quite often because they satisfy the conditions of fresh vegetable and production brands for consumers [3]. Most traditional markets are not origin about vegetables and not satisfy the requirements of consumers who buy fresh vegetables. So, the questions here are about the consumption marketing channels and information channels to the customer. This reflected the consumer psychology.

\section{Discussion}

Fresh vegetable business enterprise, manufacturers and farmers should set up the brand for the economic branch of fresh vegetable production at Ho Chi Minh city and strengthen consumer confidence.

The fresh vegetable market is now quite extensive, especially in the current period when the economic conditions are developed and integrated into Trans-Pacific Partnership Agreement-TPP; then to set up the economic sector of fresh vegetables plantation to meet the requirement of the need of consumer to use fresh vegetables, especially in Ho Chi Minh city. Furthermore, it meets the needs of exports of HCM city in Vietnam.

Economic efficiency of fresh vegetable planting brings enormous implications for society:

First: For consumers, farmers, manufacturers and fresh vegetable business companies;

They strengthen community health and reduce the burden of health care costs for people. This was the media agency reported about the importance of using of fresh vegetables.

Consumers had travel restriction because there was full information about the products such as fresh vegetable origin.

They meet the needs of consumers and to solve business market of fresh vegetables.

They make concentrated production to reduce transport costs.

They improve the quality of the product value and set up the brand for the locality area to create the confidence for consumers; and then, it creates more benefits to the social workers and meets the need of the Ho Chi Minh city people for fresh vegetables. On the other hand, it will increase the income of farmers as direction to export to Asian sector and in the world.

Second: For the management authorities;

The management authorities should strengthen macro-economic policies to restore the land use planning of fresh vegetable plantation economic sector in the next few years in order to meet the needs of the fresh vegetable using of the Ho Chi Minh city. The quality and food safety will be managed.

\section{Conclusion}

Results of factor analysis and expenditure test showed that factors have effects on age, price and living conditions, income and education, trade of sologan and distributor, agricultural land, weather and environmental knowledge; consumer business market research really affect the social condition of the formation of the economic land area of fresh vegetables plantation at the suburb of Ho Chi Minh city.

On the other hand, the income levels of people are increasing gradually, and the consumer demand for food is increasing. But sellers do not capture all the needs of consumers. In addition, consumers do not know the correct information about the product of 
fresh vegetables because there is no basis to distinguish the fresh vegetables with normal vegetables. The lack of information in the fresh vegetable business market, has limited a small of fraction on potential market. Therefore, to develop stronger fresh vegetables business market at Ho Chi Minh city as well as export demand, it needs to promote more information for consumers about how to understand the benefits of the using of fresh vegetables. Beside, the authorities should have the effective management solutions of production, distribution and business traffic to ensure the quality of fresh vegetables.

This study is limited by the objects of research which are the social and environment factors affecting the formation of the economic land area of fresh vegetables plantation at the suburb of Ho Chi Minh city and the scope of study is Ho Chi Minh city but authors also can use the results of this study to make the material for the research of analyzing in Can Tho city, Tay Ninh Province or other cities.

From the results of analysis the economic efficiency had brought the social community the formation of the economic land area of fresh vegetables plantation at the suburb of Ho Chi Minh city which is possible to develop in the near future.

\section{References}

[1] Department of Agriculture and Rural Development of Ho Chi Minh City. 2005-2010. Statistical report.

[2] Statistical yearbook of Ho Chi Minh City. 2006-2010. Statistical Data, Year books.

[3] The Discussion of Consumer in the Surveyed Areas. 2016. District 1,3 and Tan Binh District.

[4] The Survey Area of Crop Cultivation Farmers. 2016. Binh Chanh, District 12, Thu Duc Hoc Mon, Cu Chi District.

[5] National Strategy on Nutrition of Ho Chi Minh City. 2011-2015. Statistical report.

[6] The Standard of New Poverty of Ho Chi Minh City. 2014-2015. Decision-2014 of People Committee of Ho Chi Minh City. 